\title{
LETTER
}

doi:10.1017/\$1041610210000062

\section{Adjunct treatment with levodopa in a patient with dementia with Lewy bodies, delusions and severe neuroleptic hypersensitivity syndrome: some comments}

Some patients with dementia with Lewy bodies (DLB) exhibit persistent disturbing psychiatric symptoms or challenging behavior despite treatment with cholinesterase inhibitors. Such patients pose one of the more difficult clinical management problems faced in psychogeriatrics. Neuroleptics are quite rightly avoided whenever possible and the cautious "start low/go slow" maxim, which most clinicians apply when neuroleptics have to be used, often turns into a chronic "stay low/get no (response)" situation. Memantine has recently been reported to produce cognitive and global benefits but without any significant improvement in psychiatric symptoms (Aarsland et al., 2009) and there are no other specific treatment recommendations for this clinical scenario.

Dr. Majic and colleagues (2010, this issue) describe the successful use of a high dose of clozapine in conjuction with levodopa to ameliorate motor side effects. Although heroic pharmacotherapy is seldom to be advocated, and particularly not in DLB patients who are especially vulnerable to side effects, Dr. Majic's case report suggests that the effective management of psychosis may sometimes be achieved by simultaneously treating with clozapine and levodopa. Further closely monitored case studies are needed to see if this is indeed the case and readers of International Psychogeriatrics might like to contact me directly by email (i.g.mckeith@ncl.ac.uk) with reports positive or negative - of their experiences with this combination, or indeed other treatments they have used to manage "difficult" DLB psychosis.

\section{Reference}

Aarsland, D. et al. (2009). Memantine in patients with Parkinson's disease dementia or dementia with Lewy bodies: a double-blind, placebo-controlled, multicentre trial. Lancet Neurology, 8, 613-618.

Majic, T., Mell, T., Heinz, A. and Rapp, M. A. (2010). Adjunct treatment with levodopa in a patient with dementia with Lewy bodies, delusions and severe neuroleptic hypersensitivity syndrome: case report. International Psychogeriatrics, epublished ahead of print. doi:10.1017/S1041610210000190.

\section{IAN MCKEITH}

Institute for Ageing and Health, Newcastle University, Newcastle upon Tyne, U.K.

Email: i.g.mckeith@ncl.ac.uk 